www.jmscr.igmpublication.org

Impact Factor 5.84

Index Copernicus Value: 83.27

ISSN (e)-2347-176x ISSN (p) 2455-0450

crossref DOI: _https://dx.doi.org/10.18535/jmscr/v5i6.208

Journal Of Medical Science And Clinical Research

\title{
Assessment of Psychological Morbidity among First Year Medical Students
}

\author{
Authors \\ Manmeet Singh ${ }^{1}$, Vanita Gupta ${ }^{2}$
}

${ }^{1}$ Assistant Professor, Dept of Psychiatry, Acharya Shri Chander College of Medical Sciences, Jammu (J\&K)

${ }^{2}$ Professor \& HOD, Dept of Anatomy, Acharya Shri Chander College of Medical Sciences, Jammu (J\&K)

Corresponding Author

Vanita Gupta

Department of Anatomy, Acharya Shri Chander College of Medical Sciences, Jammu (J\&K)

Email:doctorvanita@yahoo.co.in

\begin{abstract}
Background: Medical Curriculum is highly stressful. Stepping into a new environment, huge course syllabus which has to be mastered in a short period of time besides continuous assessments, examinations and other social and personal issues makes a newly joined medical student prone to develop negative emotional symptoms.
\end{abstract}

Objective: This study is an attempt to assess the level of depression, anxiety and stress among first year medical students.

Materials and Methods: A cross sectional study was conducted on 97 first year medical students of ASCOMS, Jammu, Jammu \& Kashmir, India. Depression, anxiety and stress was assessed by administering a self reporting DASS-42 questionnaire. Statistical analysis- SPSS version 16 was used for statistical analysis and Pearson Chi-square was applied for statistical significance.

Results: There was significant level of depression, anxiety and stress among first year medical students. The mean depression, anxiety and stress score was $1.31 \pm 1.38,1.71 \pm 1.3$ and $1.08 \pm 1.41$ respectively. The prevalence of depression was $58.76 \%$, anxiety was $69.07 \% \%$ and stress was $54.63 \%$.The incidence of depression and anxiety was highest which showed statistical significance $(p<0.05)$ and females were affected more than males.

Conclusion: A significant proportion of first year medical students are affected with depression, anxiety and stress. The impact of negative emotional symptoms and the relevant contributing factors have to be understood. Early and timely intervention should be done addressing the negative psychological states.

Keywords: Stress, Anxiety, Depression.

\section{INTRODUCTION}

WHO defines "Health is a state of complete physical, mental and social well-being and not merely the absence of disease or infirmity." The positive dimension of mental health is stressed in WHO's definition as a state of well-being in which every individual realizes his or her own potential, can cope with the normal stresses of life, can work productively and fruitfully, and is able to make a contribution to her or his community. ${ }^{[1]}$

Medical school is recognized as a stressful environment that often has a negative effect on 
students' academic performance, physical health, and psychosocial well-being. ${ }^{[2]}$ More than half of the medical undergraduate students were found to be affected by depression, anxiety and stress. ${ }^{[3]} \mathrm{A}$ first year MBBS student, has to undergo rigorous training. There is a sudden transition from intermediate $(10+2)$ to MBBS, where in there is a huge difference in syllabus which makes a student prone to stress. In first year MBBS, there are three subjects to be covered and a student has to undergo training covering all three subjects including both theory and practical. Because of huge course and long hours of lectures students are constantly under stress. ${ }^{[4]}$ Apart from this it takes time for the students to adapt to the new environment. ${ }^{[5-7]}$ The students who are not from English background have to put an extra effort to understand the classes which are exclusively taught and discussed in English. ${ }^{[8]}$ To master the medical subjects is a huge task which is a time consuming process. This may lead to fluctuation in their diet and sleeping patterns. $\left.{ }^{[9}\right]$ Those students who can't cope up with this kind of lifestyle may undergo depression or anxiety. Underperformers are more prone to develop stress. Even academically good students show anxiety due to peer competition to constantly deliver good results. Besides students residing in hostels have to remain away from their families which puts an extra psychological pressure which is another contributing factor in development of stress/depression. ${ }^{[10]}$

The potential consequences of stress, anxiety and depression in the long run may result in social consequences in the form of substance abuse, suicidal tendencies, inter-personal relation difficulties. ${ }^{[11,12]}$

Very few studies have assessed the negative emotional symptoms in newly joined medical students in India. So we have conducted this study to assess the level of psychological morbidity and their contributing factors among first year medical students in a private medical college in Jammu \& kashmir, India.

\section{MATERIALS AND METHODS}

This study was carried out in the Acharya Shri Chander College of Medical Sciences, Jammu.

Study population: 97 first year medical students. Study design: Cross sectional study.

Inclusion criteria: This study was carried out among 97 first year medical students of Acharya Shri Chander College of Medical Sciences who had completed more than 6 months in college.

Exclusion criteria: 1.Any self-reported physical illness 2.Students with any psychiatric disorders.

It was a questionnaire based study. It was completely based on voluntary participation. Before administering the questionnaire the nature of the study was explained to the students in detail. Informed consent was taken from all the participants and complete confidentiality was assured. Ethical committee approval was taken prior to the study.

We administered DASS in its original version. Any difficult terminology was duely clarified. The DASS is a 42 -item questionnaire which includes three self-report scales designed to measure the negative emotional states of depression, anxiety and stress. ${ }^{[13]}$ Each of the three scales contains 14 items, divided into subscales of 2-5 items with similar content. The Depression scale assesses dysphoria, hopelessness, devaluation of life, selfdeprecation, lack of interest/involvement, anhedonia and inertia. The Anxiety scale assesses skeletal muscle effects, situational anxiety, and subjective experience of anxious affect. The Stress scale (items) is sensitive to levels of chronic nonspecific arousal. It assesses difficulty relaxing, nervous arousal, and being easily upset/agitated, irritable/over-reactive and impatient. Respondents are asked to use 4-point severity/frequency scales to rate the extent to which they have experienced each state over the past week. Scores of Depression, Anxiety and Stress are calculated by summing the scores for the relevant items. The depression scale items are 3, 5, 10, 13, 16, 17, 21, $24,26,31,34,37,38,42$. The anxiety scale items are $2,4,7,9,15,19,20,23,25,28,30,36,40,41$. 


\section{JMSCR Vol||05||Issue||06||Page 24071-24076||June}

The stress scale items are $1,6,8,11,12,14,18$, 22, 27, 29, 32, 33, 35, 39.

Statistical Analysis: Statistical tool SPSS version 16 was used for data analysis and Pearson Chi-Square test was applied for statistical significance.

\section{RESULTS}

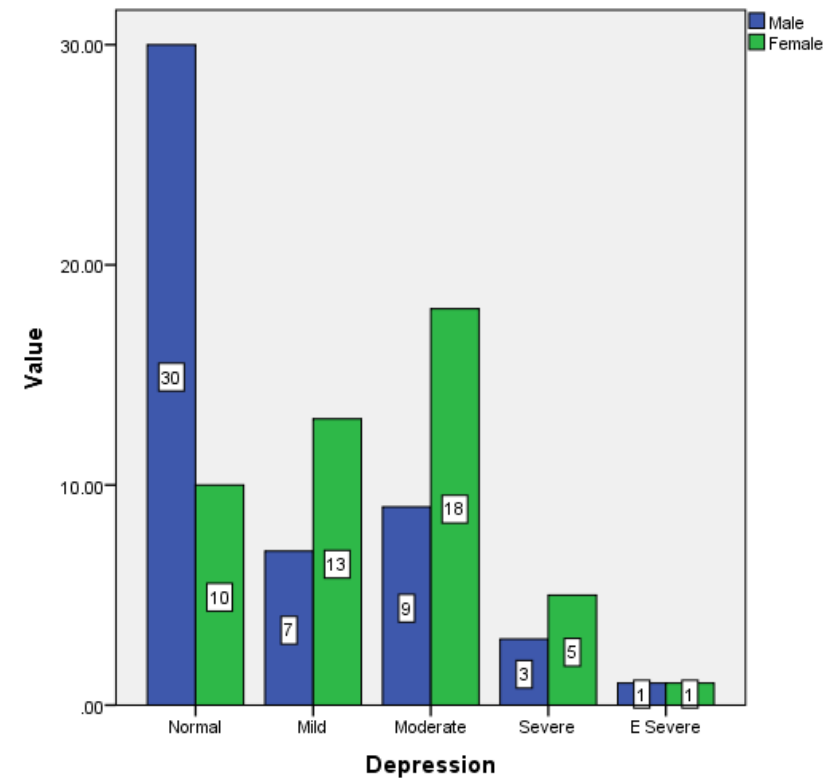

$X^{2}=14.99, p=0.001$

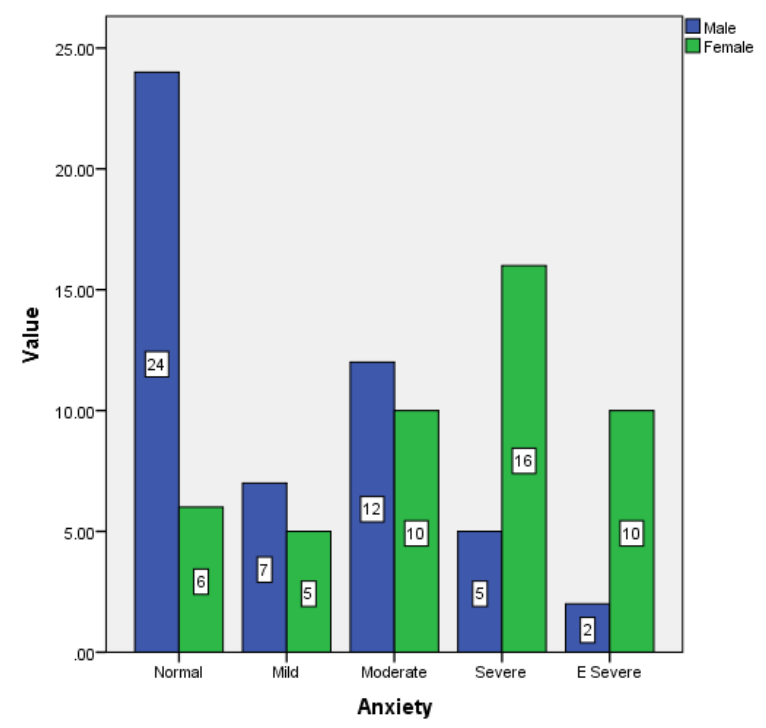

$\mathrm{X}^{2}=8.25, \mathrm{p}=0.004$

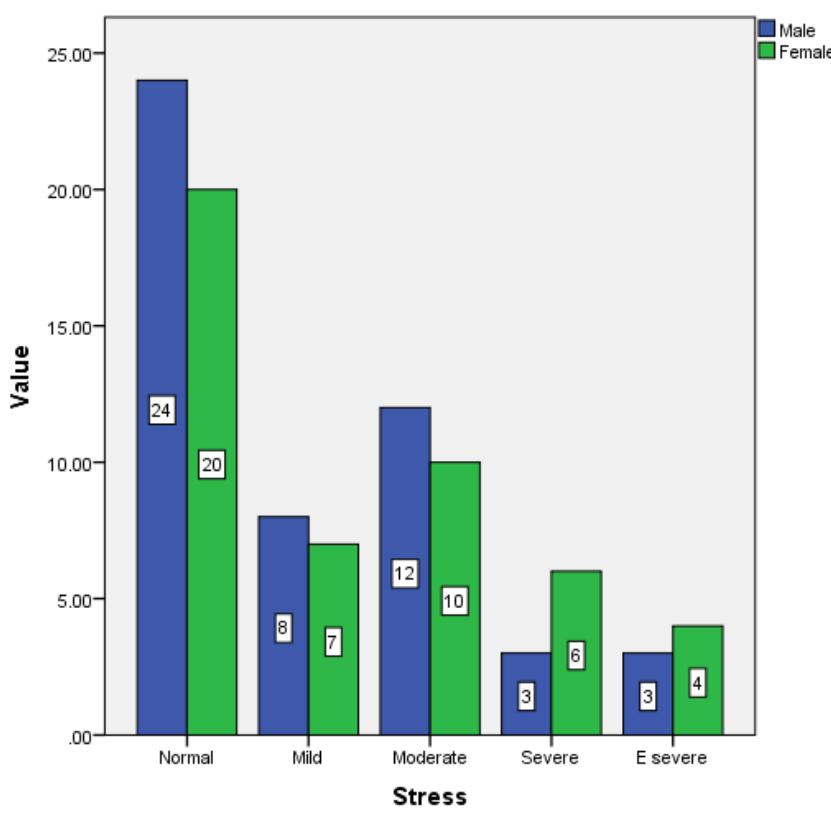

$\mathrm{X}^{2}=0.29, \mathrm{p}=0.59$

In depression scale, out of 97 students 40 showed no evidence of depression, 20 showed mild depression, 27 had moderate, 8 had severe and 2 had very severe depression. The mean depression score was $1.31 \pm 1.88$. In the anxiety scale 30 were normal, 12 suffered mild, 22 had moderate, 21 had severe and 12 students had very severe anxiety. The mean anxiety score was $1.71 \pm 1.3$. In stress scale 44 were normal, 15 students had mild stress, 22 students suffered from moderate stress, 9 students had severe and 7 of them suffered from very severe stress. The mean stress score was $1.08 \pm 1.14$.

The prevalence of depression and anxiety was highest and more among females $(\mathrm{p}<0.05)$ as compared to males. The prevalence of stress level was same both in males and females and not statistically significant.

\section{DISCUSSION}

In our study an attempt has been made to assess the level of depression, anxiety and stress among first year medical students. Medical curriculum is highly stressful. ${ }^{[14]}$ Huge amount of course has to be mastered in a short period of time. In this study $58.76 \%$ of the students showed depression and $69.07 \%$ showed anxiety of different grades (mild, moderate \& severe) which was statistically significant. 
The stress was about $54.63 \%$ among the students. Various studies have shown that high incidence of stress, anxiety and depression among first year medical students. ${ }^{[10]}{ }^{[15-18]}$ Our results were not consistent with findings of $12.2-15.7 \%$ prevalence of mental disorder in a community-based study at Dhaka ${ }^{[19]}$ and among the young male university students. ${ }^{[20]}$ Higher prevalence of mental distress was observed among the medical students at Tehran ${ }^{[21]}$ and São Paulo, Southeastern Brazil. ${ }^{[22]}$ It reveals that prevalence of mental disorder was varied in different studies. The reason might be that the studies conducted in different settings and different groups of population, scale used and cut-off point considered for assessing mental distress was not same in all these studies. It might also be due to the differences in the infrastructure of medical colleges where the studies were performed have a direct effect on the teaching-learning process and consequently on the prevalence of mental distress and influences of genetic and behavioral factors prevailing at different places. ${ }^{[23]}$

We observed that prevalence of depression and anxiety was significantly more among the female students in comparison to male students. Similar result was seen in previous studies. ${ }^{[24,25]}$ Similar to our study it has been reported that women had proportionately higher rates of stress and depressive symptoms in both the general population and the population of students of medicine which is in concordance to our study [26], [27] Fisher et al. also found that female students had increased levels of depression, anxiety, and phobias compared with their male counterparts. Being female, the environment and social support they are exposed in most cultures might be cause for the higher prevalence of mental distress among the females. ${ }^{[28]}$ Similarly in the study conducted in Japan ${ }^{[29]}$ it was observed that female students showed increased levels of psychological symptoms using a range of measures as compared to their male colleague. However, the cause of increased anxiety in females could be due to their increased enthusiasm for academic excellence, competitiveness or may be due to lack of physical exercise.

\section{CONCLUSION}

Findings of this study indicated that psychological morbidity was common in medical students and this phenomenon was more obvious among female students. The psychological well-being of medical students needs to be more carefully addressed, and closer attention to eliminate the risk factors may prevent consequent distress.

Further studies based on larger sample sizes are recommended to explore causes, consequences, and solutions for this problem rather than simply describing it. Our findings emphasize the importance of screening for mental distress of medical students during training on a regular basis for early detection and then taking appropriate intervention and steps like group counseling or stress management training.

\section{REFERENCES}

1. C Thomas. Assesment of Mental Distress in Undergraduate Medical Students. Journal of Educational Research \& Medical Teacher 2014;2(1):14-17

2. Coumaravelou Saravanan and Ray Wilks, 'Medical Students' Experience of and Reaction to Stress: The Role of Depression and Anxiety," The Scientific World Journal, vol. 2014, Article ID 737382, 8 pages , 2014. doi:10.1155/2014/737382

3. Shawaz Iqbal, Sandhya Gupta \& E. Venkatarao. Stress, anxiety \& depression among medical undergraduate students \& their socio-demographic correlates. Indian J Med Res 141, March 2015, pp 354-357.

4. Dahlin M, Joneborg N, Runeson B. Stress and depression among medical students: a cross-sectional study. Med Educ 2005; 39: 594-604.

5. Somnath T. Salgar International Journal of Biomedical And Advance Research ISSN: 2229-3809

(Online) 
Journal.DOI:http://dx.doi.org/10.7439/ijba r.v5i1.580.

6. Stewart SM, Betson C, Lam TH, Marshall IB, Lee PW, Wong CM. Predicting stress in first year medical students: a longitudinal study.Med Educ. 1997 May; 31(3):163-8.

7. Nor Iza A Rahman, Salwani Ismail, Tengku Nur Ain Binti Tengku Seman, Nur Farah Atikah Binti Rosli, Siti Aisyah Binti Mat Jusoh, Wan Putri Elena Wan Dali, Md. Zakirul Islam, Mainul Haque. Stress Among Preclinical Medical Students of University Sultan Zainal Abidin. Journal of Applied Pharmaceutical Science. November, 2013; Vol. 3 (11), pp. 076-081. DOI: $10.7324 / J A P S .2013 .31113$

8. Ayat R. Abdallah, Hala M. Gabr. International Research Journal of Medicine and Medical Sciences Vol. 2(1), pp. 11-19, February 2014 ISSN: 2354-211X.

9. Kallingappa PB, Asokan S. Psychosocial perspective of first year medical students entered in a professional course - a cross sectional study from Davangere, Karnataka. Medical Science. 2014; 2(2): 110-6.

10. Patnaik KK, Samuel CM, Pathrudu GB, RamLakshmi YVA, Bahmed F, Bodhe A.. Depression, anxiety \& stress among first year medical students: A cross sectional study. IOSR Journal of Dental and Medical Sciences (IOSR-JDMS) .Volume 14, (Oct. 2015), PP 25-28

11. Vaz RF, Mbajiorgu EF, Acuda SW .A preliminary study of stress levels among first year medical students at the University of Zimbabwe.Cent Afr J Med. 1998 Sep; 44(9):214-9.

12. Mancevska S, Bozinovska L, Tecce J, Pluncevik-Gligoroska J, SivevskaSmilevska E.Bratisl Lek Listy. Depression, anxiety and substance use in medical students in the Republic of Macedonia. 2008; 109(12):568-72.
13. Lovibond SH, Lovibond Pf. Manual for the Depression anxiety Stress Scales. (2nd Ed) Sydney, Psychology Foundation; 1995.

14. Supe AN. A study of stress in medical students at Seth G.S.Medical College. J Postgrad Med. 1998 Jan-Mar;44(1):1-6.

15. Shawaz Iqbal, Sandhya Gupta \& E. Venkatarao. stress, anxiety \& depression among medical undergraduate students \& their socio-demographic correlates. Indian J Med Res 141, March 2015, pp 354-357.

16. Abdulghani HM, AlKanhal AA, Mahmoud ES, Ponnamperuma GG, Alfaris EA. Stress and its effects on medical students: A cross-sectional study at a college of medicine in Saudi Arabia. J Health Popul Nutr 2011;29:516-22.

17. Mannapur B, Dorle AS,Hiremath ID, Ghattargi CH, Ramadurg U,Kulkarni KR. A study of psychological stress in undergraduate medical college students at S.N. medical college, Bagalkot, Karnataka. J Clin Diagn Res 2010;4:2869-74.

18. Amr M, Hady El Gilany A, El-Hawary A. Does gender predict medical students' stress in mansoura, egypt? Med Educ Online 2008;13:12.

19. Karim E, Alam MF, Rahman AH, Hussain AA, Uddin MJ, Firoz AH. Prevalence of mental illness in the community. Teach Assoc RMC 2006; 19:18-23.

20. Verger P, Combes JB, Kovess-Masfety V, Choquet M, Guagliardo V, Rouillon F, et al. Psychological distress in first year university students: Socioeconomic and academic stressors, mastery and social support in young men and women. Soc Psychiatry Psychiatr Epidemiol 2009; 44:643-50.

21. Shariati M, Yunesian M, Vash JH. Mental health of medical students: A crosssectional study in Tehran. Psychol Rep 2007;100:346-54. 
22. Lima MC, Domingues Mde S, Cerqueira AT. Prevalence and risk factors of common mental disorders among medical students. Rev Saude Publica 2006;40:1035-41.

23. Chatterjee C, Mandal PK, MallikS, Manna N, Sardar JC, Dasgupta S. A study on mental distress among MBBS students in a Medical College, Kolkata, India. Ann Trop Med Public Health 2012;5:453-7

24. Farwa Rizvi, Ayisha Qureshi, Abdul Majid Rajput and M. Afzal. Prevalence of Depression, Anxiety and Stress (by DASS Scoring System) among Medical Students in Islamabad, Pakistan. British Journal of Medicine \& Medical Research. 2015; 8(1): 69-75.

25. Inam S N, Saqib A, Alam E. J. Prevalence of anxiety and depression among medical students of private university Pak. Med. Asso. 2003 Feb 53 (2) 44-7.

26. Goebert D, Thompson D, Takeshita J, Beach $\mathrm{C}$, Bryson $\mathrm{P}$, Ephgrave $\mathrm{K}$, et al. Depressive symptoms in medical students and residents: A multischool study. Acad Med 2009;84:236-41.

27. Lloyd C, Gartrell NK. Sex differences in medical student mental health. Am J Psychiatry 1981;138:1346-51

28. Fisher S, Hood B. Vulnerability factors in the transition to university. Br J Psychol 1987;78:309-20.

29. Watanabe N. A survey of mental health of university students in Japan. Int Med J 1999;6:175-9. 